\title{
A study of Antenatal risk factors and fetal outcome in IUGR pregnancies
}

\author{
Zubair DS ${ }^{1}$, Gour SS ${ }^{2}$ \\ ${ }^{1}$ Dr Deeba Shafi Zubair, Senior Consultant, Gynecologist, Alshifa Multi Speciality Hospital Jamianagar, New Delhi, ${ }^{2}$ Dr Shivani Sachdev Gour, \\ Senior Consultant, Gynecologist, SCI Heathcare Greater Kailash One, New Delhi
}

Address for correspondence: Dr Deeba Shafi Zubair, Email: deebazubair@gmail.com

\begin{abstract}
Introduction: Low birth weight (LBW) (neonate weighing $<2500 \mathrm{~g}$ ) is a multifactorial phenomenon.Many maternal and fetal factors are found significantly to be associated with the low birthweight. Material and Methods: It was a retrospective record based study carried out in tertiary care hospitals in Delhi where the authors work between May 2013 and December 2014. The study population consisted of 200 IUGR cases (babies weighing less than $2 \mathrm{kgs}$ ). Results: In our study, maximum 80 (40\%) of the IUGR cases found in primigravidas, and minimum 24 (12\%) cases were found in $4^{\text {th }}$ gravida. In our study $82(41 \%)$ of the IUGR cases found in Normotensives, $59(29.5 \%)$ cases were found in mild hypertensives and minimum $18(09 \%)$ cases were found in severe hypertensive mothers. In our study $90(45 \%)$ of the IUGR cases found in pregnant women had normal haemoglobulin levels, maximum $56(28 \%)$ cases found in pregnant women had mild anemia and minimum 12 $(06 \%)$ cases found in pregnant women had severe anemia. Conclusion: From the available literature reviewed it was found that the major risk factor for IUGR was lack of knowledge in the mothers regarding prevention of IUGR. Hence there is a need to assess the knowledge of rural primigravidas mothers and conduct a structured teaching programme on prevention of IUGR.
\end{abstract}

Keywords: Antenatal, IUGR, Low birth weight, Pregnancy, Risk factors

\section{Introduction}

Intra uterine growth restriction is a global issue and an important public health problem which is associated with increased neonatal mortality. The birth of an intra uterine growth restricted baby evokes considerable psychological stress in the mothers which is directly related to lack of knowledge in these mothers regarding IUGR [1]. Low birth weight (LBW) (neonate weighing $<2500 \mathrm{~g}$ ) is a multifactorial phenomenon [2]. Many maternal and fetal factors are found significantly to be associated with the low birthweight [3]. World Health Organization definition of low birth weight (LBW) babiesi.e.birth weight less than 2500 gm [4]. IUGR is observed in about $23.8 \%$ of the newborn and approximately 30 million babies suffer from IUGR every year [5]. Nearly $75 \%$ of all affected babies are born in Asia, 20\% in Africa and about 5\% in Latin America. The prevalence of low birth weight in India was found to be $26 \%$ [6]. The proportion of IUGR was found to be $54.2 \%$ in India [5]. Major risk factor for IUGR was lack of knowledge in the mothers regarding prevention of IUGR. Hence researcher felt the need to assess the knowledge of rural primigravida mothers and conduct a structured teaching programme on prevention of IUGR.

\section{Material and methods}

Study design: Retrospective record based study.

Study period: May 2013 and December 2014.

Study place: The study was carried out in tertiary care hospitals in Delhi.

Study population: The study population consisted of 200 IUGR cases (babies weighing less than $2.5 \mathrm{kgs}$ ) from the hospital records. Procedure: The records of the study group were studied retrospectively and the high risk factors in the antenatal period and the fetal outcome were compared.

Manuscript received $2^{\text {nd }}$ February 2016 Reviewed: $12^{\text {th }}$ February 2016 Author Corrected: $24^{\text {th }}$ February 2016 Accepted for Publication $8^{\text {th }}$ March 2016
Statistical analysis: The data was entered in the Microsoft office excel 2007 and analyzed using Epi-info software (available free online).

\section{Results}

Table No 1: Distribution of IUGR cases according to the maternal age.

\begin{tabular}{|l|l|l|}
\hline Maternal age in years & $\begin{array}{l}\text { No. of IUGR } \\
\text { cases }\end{array}$ & Percentage \\
\hline$\leq 20$ & 38 & 19 \\
\hline $21-30$ & 100 & 50 \\
\hline $31-40$ & 40 & 20 \\
\hline$\geq 40$ & 22 & 11 \\
\hline Total & $\mathbf{2 0 0}$ & $\mathbf{1 0 0}$ \\
\hline
\end{tabular}

In our study $38(19 \%)$ of the IUGR cases found in $\leq 20$ year age group, maximum $50(20 \%)$ cases were found in $21-30$ year age group and minimum $22(11 \%)$ cases were found in $21-30$ year age group.

Table No 2: Distribution of IUGR cases according to the parity.

\begin{tabular}{|l|l|l|}
\hline Parity & No. of IUGR cases & Percentage \\
\hline Primi & 80 & 40 \\
\hline G2 & 52 & 26 \\
\hline G3 & 44 & 22 \\
\hline G4 & 24 & 12 \\
\hline Total & $\mathbf{2 0 0}$ & $\mathbf{1 0 0}$ \\
\hline
\end{tabular}

In our study, maximum $80(40 \%)$ of the IUGR cases found in primigravidas, and minimum $24(12 \%)$ cases were found in $4^{\text {th }}$ gravida. 
Table No 3: Distribution of IUGR cases according to the weight gain during pregnancy.

\begin{tabular}{|l|l|l|}
\hline Weight gain & No. of IUGR cases & Percentage \\
\hline$<4 \mathrm{Kg}$ & 53 & 26.5 \\
\hline$>4 \mathrm{Kg}$ & 147 & 73.5 \\
\hline Total & $\mathbf{2 0 0}$ & $\mathbf{1 0 0}$ \\
\hline
\end{tabular}

In our study $53(26.5 \%)$ of the IUGR cases were found. Total weight gain during pregnancy is less than $4 \mathrm{Kg}$ and $147(73.5 \%)$ cases were found where the total weight gain during pregnancy is more than $4 \mathrm{Kg}$.

Table No 4: Distribution of IUGR cases according to the pregnancy induced hypertension.

\begin{tabular}{|l|l|l|}
\hline PIH & No. of IUGR cases & Percentage \\
\hline Normotensive & 82 & 41 \\
\hline Mild & 59 & 29.5 \\
\hline Moderate & 41 & 20.5 \\
\hline Severe & 18 & 09 \\
\hline Total & $\mathbf{2 0 0}$ & $\mathbf{1 0 0}$ \\
\hline
\end{tabular}

In our study $82(41 \%)$ of the IUGR cases found in Normotensives, $59(29.5 \%)$ cases were found in mild hypertensives and $18(09 \%)$ cases were found in severe hypertensives.

Table No 5: Distribution of IUGR cases according to the anemia.

\begin{tabular}{|l|l|l|}
\hline Anemia & No. of IUGR Cases & Percentage \\
\hline Normal & 90 & 45 \\
\hline Mild & 56 & 28 \\
\hline Moderate & 42 & 21 \\
\hline Severe & 12 & 06 \\
\hline Total & $\mathbf{2 0 0}$ & $\mathbf{1 0 0}$ \\
\hline
\end{tabular}

In our study almost $45 \%$ of IUGR babies delivered from mothers with normal haemoglobin.

\section{Discussion}

In our study, IUGR was found more commonly in the age group of less than 20 years and least common in the age group of more than 40 years. This observation is comparable with the study conducted by Moore who found IUGR to be more common in less than 20 years age group [7]. In our study, maximum $80(40 \%)$ of the IUGR cases found in primigravidas, and minimum $24(12 \%)$ cases were found in $4^{\text {th }}$ gravida. This finding is in concordance with the findings of Arora et al [8]. In our study, 53 (26.5\%) of the IUGR cases found where the total weight gain during pregnancy was less than $4 \mathrm{Kg}$ and $147(73.5 \%)$ cases were found where the total weight gain during pregnancy is more than $4 \mathrm{Kg}$. these results were comparable to the study conducted by Arora et al, [8] who showed that patients with IUGR had less weight gain during pregnancy. Similarly Abrams et al [9] found that underweight women with poor weight gain during pregnancy have greater risk of delivering infants less than 2500 grams. In our study, the incidence of pregnancy induced hypertension with IUGR was 59\%. These findings are comparable to the study conducted by Arora et al [8] who found $24 \%$ of patients of IUGR to be associated with PIH, Visser et al [10] found hypertensive disorders were the most common causative factor for IUGR accounting for $59 \%$ of the cases, similarly Odegard, [11] found in a study that risk of IUGR was four times higher in infants born after preeclampsia. In our study $90(45 \%)$ of the IUGR cases found in pregnant women had normal haemoglobin levels, maximum $56(28 \%)$ cases found in pregnant women had mild anemia and minimum $12(06 \%)$ cases found pregnant women had severe anemia. Allen [12] showed that anemia was significantly associated with IUGR. The percentage of anemia was $27 \%$ in his study.

\section{Conclusion}

From the available literature reviewed it was found that the major risk factor for IUGR was lack of knowledge in the mothers regarding prevention of IUGR. Hence there is a need to assess the knowledge of rural primigravidas mothers and conduct a structured teaching programme on prevention of IUGR.

\section{Funding: Nil \\ Conflict of interest: None. \\ Permission of IRB: Yes}

\section{References}

1. Selvaraj J P. A study on IUGR. Nightingale nursing times.2007.june; 3(3):P.9-11.

2. Deshmukh JS, Motghare DD, Zodpey SP, Wadhva SK. Low birth weight and associated maternal factors in an urban area. Indian Pediatr. 1998 Jan;35(1):33-6.

3. Singh G, Chouhan R, Sidhu K. Maternal factors for low birth weight babies. Medical Journal Armed Forces India.2009;65:10-12 4. International Classification of Disease, Ninth revision, Volume 1. Geneva: World Health Organization; 1977.

5. Deonis M. Blossner M, Villar J. Levels and patterns of IUGR in developing countries. Available at http://www.unu.edu/ unupress/food2/UIDO3E/uid03e05.html

6. WHO (1995) Bridging the gaps. The World Health Report 1995. Report of the Director General.

7. Moore LG, Zamudio S, Zhuang J, Sun S, Droma T. Oxygen transport in tibetan women during pregnancy at 3,658 $\mathrm{m}$. Am J Phys Anthropol. 2001 Jan;114(1):42-53.

8. Arora. N. K, Paul. V.K, Singh Meharban- neonatal section. Journal of Paediatrics.2002 August; $14(6): 25$.

9. Abrams BF, Laros RK Jr. Prepregnancy weight, weight gain, and birth weight. Am J Obstet Gynecol. 1986 Mar;154(3):503-9.

10. Visser GH. Early fetal growth retardation. Obs Gyn1986;67(1):20-24.

11. Odegård RA, Vatten LJ, Nilsen ST, Salvesen KA, Austgulen R. Preeclampsia and fetal growth. Obstet Gynecol. 2000 Dec;96(6):950-5.

12. Allen LH. Biological mechanisms that may underlie Iron's effect on preterm birth. Journal of Nutrition. Feb 2000:581-589.

How to cite this article?

Zubair DS, Gour SS, A study of Antenatal risk factors and fetal outcome in IUGR pregnancies: Int J Med Res Rev 2016;4(5):677-678.doi: 10.17511/ijmrr.2016.i05.01. 